\title{
Extraction of Methane from Natural Product and Natural Wastes: A Review
}

\author{
T. Manoj ${ }^{\# 1,}$ D. Ravichandran $*^{2}$ \\ ${ }^{\# 1}$ PG Student, Department Of Mechanical Engineering, Nandha Engineering College,Erode-638052,India. \\ ${ }^{* 2}$ Assistant Professor, Department Of Mechanical Engineering, Nandha Engineering College, Erode 638052,India.
}

Abstract -The present day energy crisis brings the alternate way of energy production by bio gas. Bio gas is the alternative energy source and it is the one, which is economically compact and has high potential. The production of methane gas from biomass has been suggested as a lesson that tells the demand for natural gas and utilizing the reservoirs of methane on the environment. The bio gas is extracted by Anaerobic digestion of wastes, which was carried out in the batch scale under ambient temperature. The bio gas production was measured in daily basis by the liquid displacement method. The digested slurry can be used in agricultural field as a fertilizer.

Keywords- alternate energy, anaerobic process, fossil fuels, wastes.

\section{INTRODUCTION}

Biogas is the mixture of gas produced by the breakdown of organic matter in the absence of oxygen. It can be produced from available raw materials such as recycled waste. It is renewable energy with less carbon footprint. Biogas mainly contains methane $(\mathrm{CH} 4)$, carbon dioxide $(\mathrm{CO} 2)$, and rarely a small amount of hydrogen sulfide (H2S).

Methane is the simplest alkane and its relative abundance makes it as an attractive fuel. Methane is present in the nature like fruits, vegetables, seeds, etc. The methane is extracted from these sources and they can be used as a alternate source of fuel.
Methane on combustion produce a heat of $55.5 \mathrm{MJ} / \mathrm{KG}$. Natural methane is produced by methanogenesis process.

$$
\mathrm{CO}_{2}+8 \mathrm{H}^{+}+8 \mathrm{e}^{-} \rightarrow \mathrm{CH}_{4}+2 \mathrm{H}_{2} \mathrm{O}
$$

In this paper a literature survey is taken about the methane production from various natural matters. The various production techniques and their results were summarized below.

\section{LITERATURE SURVEY}

The author describes the production of methane from the municipal and industrial waste. These wastes are collected in the anaerobic digester which produce methane gas. These wastes emit 6$18 \%$ of methane to the atmosphere. Here the methane is properly utilized from the solid waste and minimize the atmospheric pollution [1]. The methane emission from cattle, ruminant livestock produce $250-500 \mathrm{~L}$ of methane per day. Methane emission is measured by mass balance and other techniques. The idea here is to reduce methane in the atmosphere to avoid global warming [2]. The author investigates the rate of conversion to methane of different fruits and their parts. Here 54 varieties of fruits and vegetables were compared with the standard biomass. The methane yield and kinetics were differing for different parts of the same variable. From this they said mango peels, citrus waste yield methane of $\mathrm{P}<0.05$, that produces $90 \%$ of methane 
in40-50 days [3]. They describe the extraction of methane from methane hydrate by using the laser as a tool. It is the superior then other methods of extraction of methane. The types of lasers suit for methane production is discussed. The most effective one is chemically pumped oxygen-iodine energy transfer, laser (COIL) [4]. The author proposed the idea of the reduction of methane and nitrous oxide in order to prevent the green house emission and also a economic analysis. The various techniques which are economically less are described properly using the methane and nitrous oxide as an alternate source [5].

The author describes the potential of bio gas production of cotton wastes like cotton oil cake, cotton seed hull and cotton stalks. The experiment was carried out under two different concentrations like 30 and $60 \mathrm{~g} / \mathrm{l}$. After the anaerobic digestion of these wastes produce 65,86 and $78 \mathrm{ml}$ of methane in 23 days for $1 \mathrm{~g}$ of stalks, seed hull and oil cake respectively. The basal medium increases the bio gas production [6]. The prediction of methane generation using simple methods in tropical landfills. Simple procedure to estimate methane production potential and biodegradation rate are discussed. The first order decay method is used here. This paper compares both the field result and the laboratory result. The laboratory result is smaller than field due to the moisture content which affect the degradation rate [7]. The methane gas is produced during the formation of coal under high temperature and pressure. This is also called coal mine methane (CMM) which is extracted from the mine by drilling, long drill.. Etc, The best optimized design is required for that full parameters and data has to know [8]. The integrated rotary drum reactor was assisted with the anaerobic phase solid digester to convert municipal waste into the bio gas. RDR was developed to separate the organic and inorganic material from solid waste. The organic matter is then used in bio reactor, it contains $50 \%$ of solid waste, volatile solid of $36 \%$. After the methane yield $38 \%$ of total solid and $53 \%$ of volatile solid was reduced. From this APS digester is effective for digestion of organic waste. Future scope is to increase the performance of APS digester by increase the rate of liquid circulation [9].

The extraction of methane from the jatropha de-oiled cake and orange peel in an anaerobic digester. The maximum gas production is obtained for the ratio 1:2 of jatropha de oiled cake and orange peel. The gas contains $75 \%$ of methane, $16 \%$ of carbon dioxide and 9\% of $\mathrm{CO}$ [10]. The author describes the anaerobic digestion of cow dung in the digester produce methane. The cow dung has $40-60 \%$ of methane. The mesopholic anaerobic digestion of $440 \mathrm{~kg}$ cow dung in the 800 liter capacity digester produces $26.478 \mathrm{~m} 3$ of bags for 77 days with an average of $61 \%$ of methane [11]. The methane production rate in first stage and second stage digester. Fruits and vegetable waste are added to both the digester after 10 days the methane in the first stage reactor was $514 \pm 57 \mathrm{~L}$ and in second stage 392 $\pm 16 \mathrm{~L}$. From this first stage reactor is suitable for high methane generation [12]. The investigation is done by the author for the effective treatment of municipal bio waste by pilot scale anaerobic digestion and it reduces the emission of greenhouse gas. Municipal waste includes fruits, sewage and food waste. The $16.5 \%$ of lipid content was useful for bio gas production before the anaerobic process starts. Thus the anaerobic co-digestion is good solution to treat municipal waste and control green house gas. CHG was reduced to 114 and $523 \mathrm{~kg} \mathrm{co}_{2}$ $\mathrm{e}^{\mathrm{t}^{-1}}$. [13] . The author examines the ratio of feedstock 
and its effect in the bio gas production. Rice husk along with the kitchen waste and pig manure was digested by anaerobic process in the single stage reactor. The effective result shows $45.9-70 \%$ of methane in the ratio $0.4: 1.6: 1$ of kitchen waste, pig manure and rice stack. The total bio gas yield for 67.44 L/KG VS is higher than pig manure and rice stack alone by $71.6 \%$ and $10.41 \%$ kitchen waste produces more than $26 \%$. The bio gas production was inhibited by lactic acid and acetate. The reduction rate of volatile solid was $55.8 \%$. By adding kitchen waste and pig manure along with rice stack the bio gas production gets higher [14].

The author examines the Phyllanthus emblica residues and food waste for the methane production. Phyllanthus emblica residues singly, not suitable for bio gas production because it contains methanogenic inhibitor. Three bio reactors were examined one for food digestion, second for PER digestion and third for co-digestion of PER and food waste. Bio-gas production from co-digestion was greater than that of other two digestion reactor. The experiment was conducted both in pilot scale and lab scale reactor. Pilot scale reactor results, $34 \%$ increase in methane production from PER and food waste codigestion [15]. The biogas production from the various waste materials such as human waste, vegetables, municipal waste etc..... The biogas contain $50-60 \%$ of methane and $25-45 \%$ of carbon dioxide. Bio gas is formed by the digestion of waste by anaerobic process [16]. The author introduces the new constructive technology to the anaerobic digester that does not need external energy, which is to clean the birds and animal waste and convert it into two useful products. The products are combustible gas and fertilizers. The advantages of this technology are small, self-regulated and produce $15-20 \%$ of combustible gas. By heating the waste the efficiency is increased. Implementing this technology with anaerobic digester the pollution can be avoided and bio gas, and fertilizers are obtained [17].

The author reviews the environmental pollution due to discharge of large amounts of food waste. The food waste was converted into bio gas by anaerobic process. The food waste characteristics, anaerobic digestion principle and parameters are studied. The volatile fatty acid was added for high methane yield and stability. The other way to improve the methane yield is by adding cattle manure along the food waste . [18].

The author here investigates the anaerobic digestion of various forestry wastes. The tropical bio waste was investigated for bio gas production by solid state and liquid state anaerobic digestion. The $\mathrm{L}-\mathrm{AD}$ produce 161 and $113 \mathrm{LKg}^{-1} \mathrm{VS}$ of methane and solid state AD produce 156.8 and $59.6 \mathrm{LKg}^{-1} \mathrm{VS}$ of methane. SS-AD achieve higher volumetric methane production than L-AD. Compare to all the leaves and woods obese have a higher methane yield. Anaerobic digester is good for treat food wastes [19]. The author studies the production of bio gas from various biomasses like lemon grass, poultry waste and cow dung. The feed is mixed with water in the ratio of $1: 1$ and left for 30 days for digestion, which produce $0.125 \mathrm{~m}^{3}, 0.211 \mathrm{~m}^{3}$ and $0.191 \mathrm{~m}^{3}$ of bio gas. Lemon grass produces lower bio gas than other two. But the quality of bio gas from lemon grass was good [20].

\section{CONCLUSION}

The various papers that described the methane production which is the alternate source of fuel in the future and its various sources and production techniques are reviewed. This survey reveals that almost the nature's entire product like 
fruits, vegetables and other natural waste has the potential to produce methane. Conversion rate of bio mass to methane was different for each bio mass type. Catalysts can add to increase the speed of the reaction. After extraction of methane large amount of de-oiled waste is produced and left unused.The wastes are recycled and converted into use full bio gas. Methane extraction from de-oiled wastes are not adequately addressed and tried.

Future scope in this area is to extract methane from the various de-oiled wastes and techniques to improve the performance of an anaerobic digester.

\section{REFERENCES}

[1] H. G. BINGEMER.., The production of methane from solid waste, journal of geophysical research, vol. 92, no. d2, pages 2181-218, February 20,1987.

[2] K A Johnson.., D E Johnson.., Methane emission from cattle, the journal of animal science 73:2483-2492 1995.

[3] V. Nallathambi Gunaseelan.., Biochemical methane potential of fruits and vegetable solid waste feedstocks, biomass and bio energy 26 (2004) $389-399$.

[4] Tomoo FUJIOKA..,Kazuya JYOSUI..,,Hiroyuki NISHIMURA.., Kazuyoku TEI..,Extraction of methane from methane hydrate using lasers, the japan society of applied physics, Vol. 42 (2003) pp. 5648-5651.

[5] Mitigation of Methane and Nitrous Oxide Emissions from Waste, Energy and Industry, the energy journal, 2006.

[6] A. Iscia.., G.N. Demirer.., Biogas production potential from cotton wastes, Renewable Energy 32 (2007) 750757.

[7] Sandro L. Machado.., Miriam F. Carvalho ..,JeanPierre Gourc.., Orencio M. Vilar.., Methane generation in tropical landfills : simplified methods and field results, waste management 29 (2009) 153-161.

[8] LI Guo-jun.., Theoretical research and practice on coal mine methane extraction and ground development design, procedia earth and planetary science 1 (2009) 94-99.

[9] Baoning Zhu..,Ruihong Zhang.., Petros Gikas.., Joshua Rapport.., Bryan Jenkins..,Biogas production from municipal solid wastes using an integrated rotary drum and anaerobic-phased solids digester system, Bioresource Technology 101 (2010) 6374-6380

[10] Periyasamy Elaiyaraju and Nagarajan Partha..,

Biogas production from co-digestion of orange peel waste and jatropha de-oiled cake in an anaerobic batch reactor, African journal of biotechnology, Vol. 11(14), pp. 3339-3345.

[11] Amel Ounnar.., Lamia Benhabyles.., Sadek Igoud.., Energitic valorization of biomethane produced from cow dung, procedia engineering 33 (2012) $330-334$.

[12] Nathan D. Park, Ronald W. Thring and Steve S. Helle..,Comparison of methane production by co-digesting fruit and vegetable waste with first stage and second stage anaerobic digester sludge from a two stage digester,water science and technology 65.7, 2012.

[13] Xiao Liu.., Xingbao Gao .., Wei Wang..,Pilot-scale anaerobic co-digestion of municipal biomass waste: Focusing on biogas

production and GHG reduction, Renewable Energy 44 (2012) $463 \mathrm{e} 468$.

[14] Jingqing Ye.., Dong Li.., Yongming Sun..,Improved biogas production from rice straw by co-digestion with

kitchen waste and pig manure, Waste Management 33 (2013) 2653-2658.

[15] Siriwan Panyadee.., Anurak Petiraksakul .., Chantaraporn Phalakornkule..,Biogas production from co-digestion of Phyllanthus emblica residues and food waste, Energy for Sustainable Development 17 (2013) 515-520.

[16] Emil Nutiu..,Anaerobic purification installation with production of biogas and liquid fertilizers, Procedia Technology 12 ( 2014 ) 632 - 636.

[17] Cunsheng Zhang.., HaijiaSu.., JanBaeyens.., TianweiTan.a ,Reviewing the anaerobic digestion of food waste for biogas production, renewableandSustainableEnergyReviews38(2014)383-392.

[18] Xumeng Ge.., Tracie Matsumoto.., Lisa Keith.., Yebo Li..,Biogas energy production from tropical biomass wastes by anaerobic digestion, bioresource Technology 169 (2014) 38-44.

[19] Dhameliya Prathmika.., Biogas Production from Different Waste Matireals in India, the international journal of science and technology, vol 2 issue 6, 2014.

[20] I.M. Alfa ..,S.O. Dahunsi ..,O.T. Iorhemen ..,C.C.Okafor .., S.A. Ajayi..Comparative evaluation of biogas production from Poultry droppings, Cow dung and Lemon grass, Bio resource Technology 157 (2014) 270-277. 